\title{
Characterization of a Ni Base Alloy Obtained by Mechanical Alloying Followed by Conventional Sintering and SPS
}

\author{
L.C. Ortiz Luévano, * I. Estrada-Guel, * S. D. De la Torre, ** J. M. Herrera-Ramírez, * \\ and R. Martínez Sánchez* \\ * Centro de Investigación en Materiales Avanzados (CIMAV), Laboratorio Nacional de \\ Nanotecnología, Miguel de Cervantes No.120, C.P. 31109, Chihuahua, Chih., México. \\ **Centro de Investigación e Innovación Tecnológica CIITEC-IPN. Calle cerrada de Cecati S/N Col. \\ Santa Catarina. Azcapotzalco, D.F., CP.02250. México.
}

Spark plasma sintering (SPS) method is a process that allows compaction of ceramics and powders metals at low temperature with short heating, holding and cooling time [1-2]. In the SPS method, raw powders in a graphite die are pressed uniaxially and a direct current pulse voltage is applied. During the procedure, the powders are heated by spark discharge between the particles and the graphite die is also heated by direct current pulse voltage, so the powder is heated from both inside and outside. In this work the microstructural effect of using SPS is compared with the effects of the conventional sintering in the mechanical properties of a Ni based alloy synthesized by mechanical alloying (MA). Raw materials were commercial cobalt, chromium and nickel pure powders supplied by Sigma-Aldrich. Compositions studied were $\mathrm{Ni}_{50} \mathrm{Co}_{45} \mathrm{Cr}_{5}, \mathrm{Ni}_{50} \mathrm{Co}_{40} \mathrm{Cr}_{10}, \mathrm{Ni}_{50} \mathrm{Co}_{35} \mathrm{Cr}_{15}$ and $\mathrm{Ni}_{50} \mathrm{Co}_{30} \mathrm{Cr}_{20}$ in at. \%. MA was performed using in a SPEX 8000 mill. An argon atmosphere was used to avoid oxidation and methanol $(1 \mathrm{ml})$ was employed as the control agent process. Powders mixtures were milled for $0,5,10,15$ and $20 \mathrm{~h}$. The ball to powder weight ratio was about 5:1. Microstructural evolution was followed by X-ray diffraction (XRD) using a Panalytical X'pert PRO diffractometer with $\mathrm{Cu} \mathrm{K \alpha}$ radiation $(\lambda=1.5406 \AA)$ and operated at $40 \mathrm{kV}$ and $35 \mathrm{~mA}$ in the $2 \theta$ range of 20-110 . Morphology and particle size were analyzed using a JEOL JSM-5800 scanning electron microscopy (SEM). Variations in chemical composition were followed by EDS. The morphology of the powders was study using secondary electrons. Microstructural characterization was performed by backscattered electrons in all the consolidated samples to reveal the contrast difference according to each present phase. Milled powder follow a behavior reported as ductile-ductile system [3]. It can be observed from Figs. 1 (a) and 1(d) the morphology of pure elemental powders mixtures and the powders after $20 \mathrm{~h}$ of milling time, respectively. Figs. 1(b) and 1(c) shows the non milled powders mixtures after conventional sintering and SPS process, respectively. In similar case, Figs. 1(e) and 1(f) shows the same comparative microstructures after $20 \mathrm{~h}$ of milling. Non-milled powders show a couple of phases in both sintering process used. The darker one is $\mathrm{Cr}$-rich phase. And the bright is a Ni-Co solid solution. Samples milled for 20h, present a more homogeneous microstructure. Darker phase present a smaller size and more homogeneous distribution. XRD analyses development a crystal size decrement as a function of milling time. Additionally, XRD peaks showed a small shift to higher and smaller $2 \theta$ degrees as the milling time was increasing. This variation in lattice parameter could be attributed to generation and elimination of structural defects [3].

References

[1] Huang SG, Van der Biest O, Li L, Vleugels J. Mater Lett 2007;61:574-7.

[2] Chen W, Anselmi Tamburini U, Garay JE. Mater Sci Eng A 2005;394:132-8.

[3] C. Suryanarayana: Mechanical Alloying and Milling, Prog. in Mat. Science, 46 (2001) 35,52 


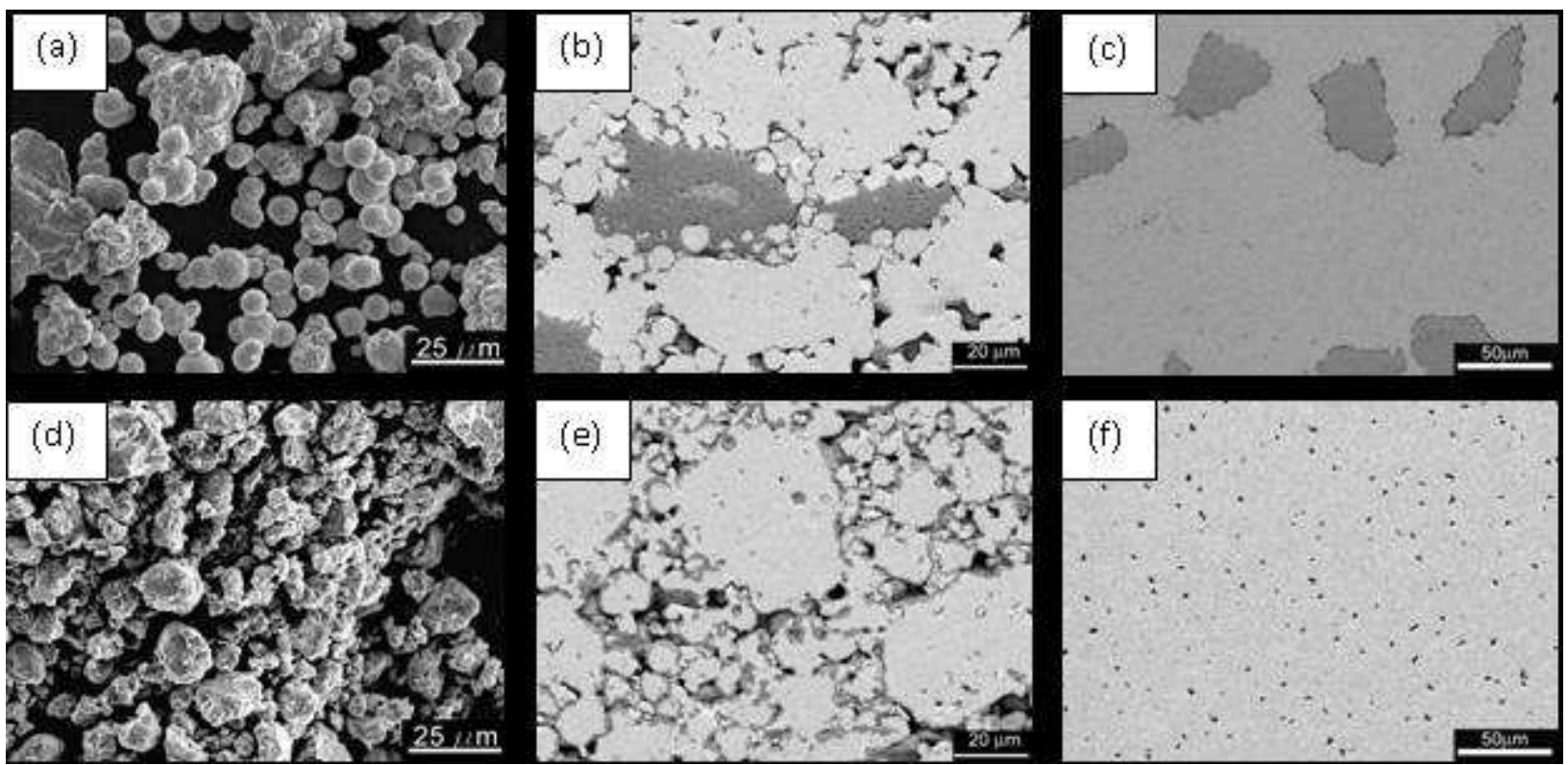

FIG. 1. $\mathrm{Ni}_{50} \mathrm{Co}_{45} \mathrm{Cr}_{5}$ (a) Powders mixture 0h milling time 1000X, (b) Conventional sintering 0h milling time 1000X, (c) SPS 0h milling time 500X, (d) powders milling time 20h 1000X, (e) Conventional sintering $20 \mathrm{~h}$ milling time $1000 \mathrm{X}$, (f) SPS 20h milling time 500X

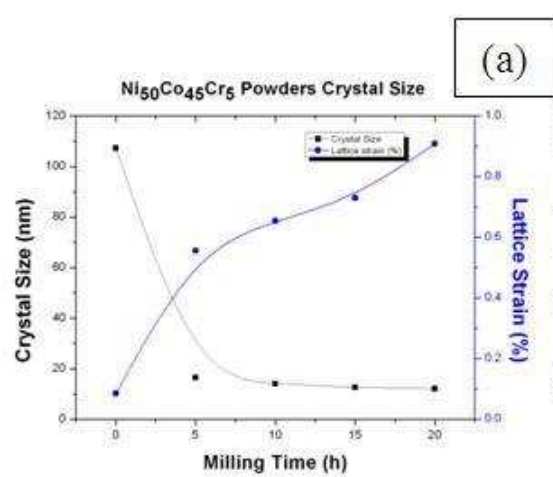

(d)

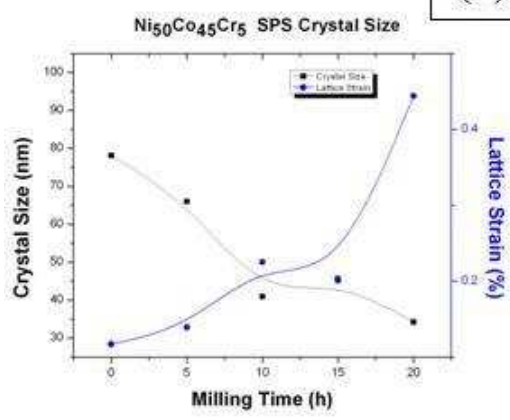

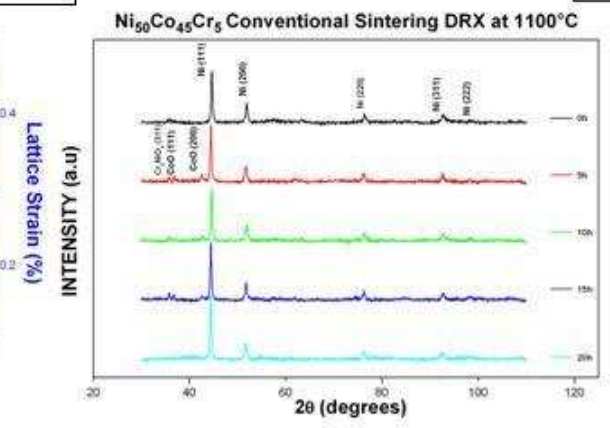

(b)

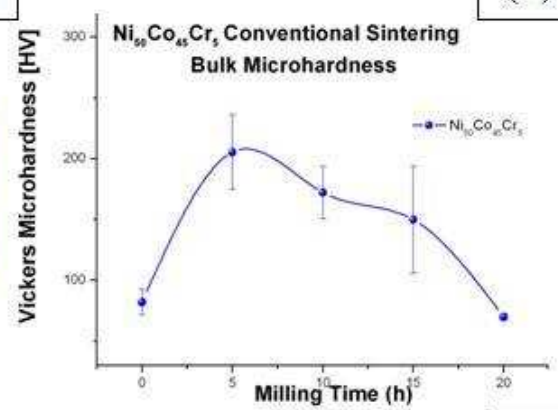

(e)

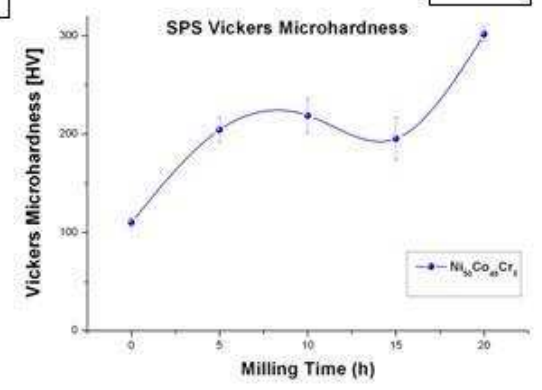

(f)

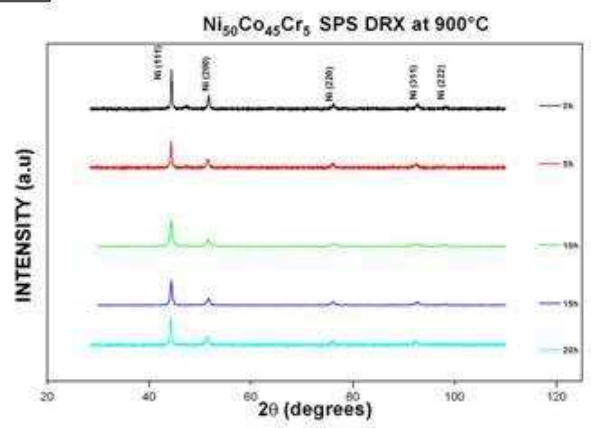

FIG. 2. $\mathrm{Ni}_{50} \mathrm{Co}_{45} \mathrm{Cr}_{5}$ : (a) Powders crystal size, (b) conventional sintering bulk microhardness, (c) SPS Vickers microhardness, (d) SPS crystal size, (e) conventional sintering DRX, (f) SPS DRX. 